\title{
Nursing students' evaluation of the introduction of nursing diagnosis focused tutorials in a university degree programme
}

\author{
P Brysiewicz, PhD \\ Senior lecturer, School of Nursing, Faculty of Health Science, University of KwaZulu-Natal
}

MB Lee, PhD

Associate Professor - at the time of conducting this research Dr. Lee was an Associate Professor in the School of Nursing, University of KwaZulu-Natal. She is currently an Associate Professor at University of North Alabama, USA

\section{$\underline{\text { Key words }}$}

Nursing diagnosis, student satisfaction, nursing education

\section{Correspondence address}

Dr Petra Brysiewicz

School of Nursing,

University of KwaZulu-Natal,

Durban, 4041

Tel : (03I) 260-1281

Fax : (031) 260-1543

Email: brysiewiczp@ukzn.ac.za

\section{Abstract: Curationis 32 (1): 20-24}

The School of Nursing at the University of KwaZulu-Natal has recently introduced the concept of nursing diagnosis within the Bachelor of Nursing Problem Based Learning (PBL) acute care nursing course.

A descriptive survey was designed to evaluate a teaching strategy the researchers developed for Year III Bachelor of Nursing students in an acute care clinical practice course. All students in Year III PBL tutorials in 2006 were included in the study.

The students were satisfied with their learning and felt competent in assessing, making and prioritizing nursing diagnoses, formulating hypotheses and using the nursing process in their care in real life nursing situations. With regard to the structured nine step process students generally were enthusiastic about this process and felt that it helped them perform better.

This paper describes how the researchers introduced nursing diagnosis and how it was received by the students. Because these students are Year III students their perceptions of this change in focus is especially enlightening and provides useful feedback to further modify the course.

\section{Background to the study}

Problem solving in nursing in general, as well as nursing education specifically is essential for nurses. Furthermore, teaching nursing students how to use the nursing problem solving process (called the nursing process), is critical to their ability to provide sound quality nursing care in the clinical area (Müller-Staub, Needham, Odenbreit, Lavin, \& Van Achterberg, 1996:5; Volpato, 2003:1; Burkhart, 2006:22). Nurses need complex thinking processes, as well as psychomotor and affective skills in order to be expert clinical practitioners (Smith Higuchi \&
Donald, 1996:145). A critical step in the nursing process, and one which has not been emphasized to date in the students involved in the research, is the process of formulating a nursing diagnosis. Nursing's unique contribution to client/patient care and the scientific basis for nursing practice is demonstrated through the nursing process, and in particular when developing the nursing diagnosis. Nursing diagnoses requires students to have a good grasp of competencies such as assessment, clinical reasoning and integration of social and basic sciences. Nursing diagnosis is meaningless without the use of all the steps in the nursing process 
but with them, it is a very powerful tool in nursing practice. The nursing process facilitates opportunities for nurses to develop critical thinking and clinical reasoning skills in deriving nursing diagnoses, designing and selecting therapeutic interventions, and evaluation of outcomes. Nursing diagnosis assists in clinical decision making that is based on critical review and utilization of theory and research pertinent to the phenomena of concern (Doenges \& Moorhouse, 2003:22). The students' abilities to use these skills are tested using a strategy called a 'triple jump' which was developed by staff at McMaster University, Canada in order to measure the problem-solving abilities of students (Callin \& Ciliska, 1983:41). The triple jump is used at the School of Nursing, University of KwaZulu-Natal as one of the student assessment tools at the end of each semester in the third year nursing programme.

To introduce the use of the nursing diagnosis and to promote systematic problem solving, the researchers (who were also the facilitators of these students) designed a four hour teaching programme, taught in two, two hour sessions. The sessions informed students of the systematic problem solving process that would be used in their 2006 PBL tutorials. Information on nursing diagnosis and its relationship to the nursing process was also included in the session. A nine-step problem solving process (developed by the researchers) was demonstrated to the students and was used in all tutorials for this course during the year. The nine steps included were:

Step 1: Present a brief description of the patient.

Step 2: Allow students in your group to pose hypotheses about what the possible problems are for this patient. Step 3: Allow students to ask you for data based on these hypotheses.

Step 4: Facilitate formulation of a revised problem list. This may require you to tell students additional data that was not requested and sharing with them what hypotheses you had for this patient.

Step 5: Allow students to ask more questions and to determine a final problem list. These should be in the form of nursing diagnoses, including possible diagnoses and risk diagnoses.
Step 6: Determine if you need additional information, i.e., are you able to determine a list of diagnoses that you can support with data? Does the group have any idea of what interventions/ nursing actions might be effective to reduce or eliminate the problems? What evidence do they have for this? This is an opportunity to get the group problem solving using information they have learned from a variety of disciplines.

Step 7: Present your list of interventions and rationale for them. Students can then question you about these actions. You will be the clinical expert. What evidence do you have that this nursing action decreases the problem you have identified in your nursing diagnosis?

Step 8: Determine what data you would need to collect to see if the problem was reduced or eliminated? If the group is unable to assist with this you will provide this along with your rationale. How will you determine if the patient is ready for discharge? What can you do to ensure that the patient is ready for discharge?

Step 9: In what other clinical situations might this information be useful? Identify related diagnoses and whether or not nursing actions identified would be useful in these cases.

These nine steps correspond to the ten assessment areas of the triple jump, which are:
1. Issue identification
2. Question generation
3. Data gathering
4. Knowledge
5. Interim problem formulation (nursing diagnosis)
6. Initial nursing interventions
7. Self assessment of learning needs
8. Problem formulation (nursing diagnosis)
9. Rank patient problems in order of priority
10. Nursing interventions for one identified problem (Callin \& Ciliska, 1983:42)

The study described in this paper was part of a larger study to implement a change in the acute care clinical nursing course in Year III of the Bachelor's degree programme and to determine if this change improved students' problem solving and nursing care planning

\section{Problem statement}

Although students are taught to problem solve through PBL sessions, they do not seem to correlate the activities in the class with the assessment strategies, such as 'triple jump, which has been shown to measure student problem solving capabilities (Makhathini \& Uys, 1996:343). The facilitators in the Year III clinical PBL course wanted to initiate a change in the manner in which PBL tutorials were run to see if adding more structure could improve student satisfaction with their own problem solving skills. In addition, students were not routinely using a component of the nursing process, the nursing diagnosis, and thus were not implementing this process in their nursing care planning and struggled with effectively planning relevant nursing care of a patient.

\section{Research question}

The following question was expected to be answered by this research:

- What are students' perceptions of the usefulness of the teaching and learning strategy implemented in the academic year 2006 in development of their problem solving and nursing process skills, specifically the development of nursing diagnosis?

\section{Ethical Considerations}

Permission to conduct this research was sought from the Head of School as well as ethical approval from the university ethics committee. The researchers provided all students willing to participate with a copy of the questionnaire, a participant information sheet as well as a written consent form, which all consenting students were asked to sign. The information sheet described the purpose of the research as well as the rights of the student to refuse to participate in the research and that this would not jeopardize their tutorials or marks in any way. The information sheet also contained the researchers contact details should the students require more details regarding the research. Data were de-identified and entered into SPSS v13 but the original data remained in a locked cup- 
board with one of the researchers and no one besides the researchers and the research assistant had access to it. Data could not be traced back to the individual students.

\section{Research design}

This descriptive survey was designed to evaluate a teaching strategy the researchers developed for Year III Bachelor of Nursing students in an acute care clinical practice course. At the end of the two semester course, after using the nine step problem solving process, the students completed a satisfaction questionnaire developed by the researchers.

\section{Population and sample}

All students in Year III PBL tutorials in 2006 (31 students) were exposed to the nine-step problem solving process and were informed of how to develop a nursing diagnosis. Convenience sampling was done and all the students agreed to participate in the study.

\section{Setting}

The setting for the study was the School of Nursing at the University of KwaZulu- Natal, Durban.

\section{Instrument}

The researchers developed a student satisfaction questionnaire which had 12 questions that were designed to determine students' perceptions about the effectiveness of the nine step strategy in facilitating their learning in the area of nursing process and specifically the nursing diagnosis. A Likert type scale was used with the following rating scale; $4=$ strongly agree, $3=$ agree, $2=$ disagree and $1=$ strongly disagree and $0=$ do not wish to answer. The questionnaire included questions that measured student perceptions of their mastery of elements of the nursing process such as: I feel competent to assess patients in order to make a nursing diagnosis and I am able to plan nursing interventions that are relevant to the nursing diagnosis. The questionnaire also included one open ended question namely; "Are there any comments that you would like to make, either positive or negative, about the way your tutorials were conducted this year?" Many problems with questionnaire analysis can be traced back to the de- sign phase of the tool and the researchers attempted to ensure that the questionnaire was developed to directly address the objectives of the study (Statpac, 2007:1).

\section{Validity and reliability}

Content validity was determined by two nurse educator experts at the University of KwaZulu-Natal. Reliability was determined by calculating a Cronbach's alpha on the completed questionnaires. The Cronbach's alpha on this sample was $r=0.86$.

\section{Data analysis}

Data were analysed using the Statistical Package for Social Sciences (SPSS) version 13 to provide descriptive and comparative information regarding student satisfaction. The open ended question was manually analysed and the researchers individually read through the responses and separately identified categories which emerged from the data. These categories were then discussed by the researchers and together consensus on the categories was reached.

\section{Findings}

A total of 31 students (three of whom were males) completed the questionnaire thus a response rate of $100 \%$ was achieved. Responses to the 12 questions were analysed using descriptive statistics and the findings are displayed in Table 1.

The highest score was noted for items 8: Having the nine step process made doing my case presentation much easier $(74.2 \%$ or $n=23)$ and item 10 : I feel more competent using the nursing process than in previous years $(74.2 \%$ or $n=23$ ). For all items on the student satisfaction questionnaire the positive scores for strongly agree and agree accounted for 90.3 to $98.6 \%$ of the responses, with $98.6 \%$ the median score for these two ratings. Scores for disagree and strongly disagree ranged from $3.2 \%$ to $6.5 \%$ on all items except item four: I know how to construct a nursing diagnosis, where $90.3 \%$ answered agree or strongly agree, with three responses missing.

The open ended question contained a number of responses from the students regarding other issues unrelated to the study, namely complaints regarding administrative issues, e.g., sick leave, the relocation of the nursing school and transport issues. All the responses regarding the new way of teaching in their third year group were positive. Two students remarked that class had now made them feel more competent as nurses.

\section{I feel competent and ready to work as a registered nurse.}

Class encouraged me not to rely on doctors diagnoses but to make my own nursing diagnosis. This helped me to care for my patients better.

The students felt that the new system in class had helped them a great deal and one student explained;

The nine steps were very helpful and I think that if the next years students will use it they will be more competent.

One of the students acknowledged that;

I've been struggling with the system at the beginning of the year and now I'm fully competent on formulating nursing diagnoses and prioritising.

\section{Discussion}

Overall the findings of this study indicate that the students were satisfied with their learning during the Year III PBL nursing course. The findings indicated that students felt competent in assessing, making and prioritizing nursing diagnoses, formulating hypotheses and using the nursing process in their care in real life nursing situations. With regard to the structured nine step process for case presentations and tutorials, students generally were enthusiastic about this process and felt that it helped them perform better in presenting their real patient cases in class.

The highest scores $(96.8 \%$ agree or strongly agree) on the questionnaire were the items that related to patient assessment, understanding the importance of making a nursing diagnosis, prioritizing nursing diagnoses, importance of making diagnoses, ability to plan nursing interventions and more competence in nursing process and nursing diagnosis than in previous years (not really practiced prior to this year). The lowest scores (only $90 \%$ 


\begin{tabular}{|c|c|c|c|c|c|c|}
\hline & $\begin{array}{l}\text { As a result of the Nursing Process/Nursing } \\
\text { Diagnosis Focused Tutorial; }\end{array}$ & $\begin{array}{l}\text { Strongly } \\
\text { Agree }\end{array}$ & Agree & Disagree & $\begin{array}{l}\text { Strongly } \\
\text { Disagree }\end{array}$ & $\begin{array}{l}\text { Do not wish } \\
\text { to answer }\end{array}$ \\
\hline 1. & $\begin{array}{l}\text { I feel competent to assess patients in order to make } \\
\text { a nursing diagnosis }\end{array}$ & $51.6 \%(\mathrm{n}=16)$ & $45.2 \%(n=14)$ & 0 & $3.2 \%(n=1)$ & 0 \\
\hline 2. & $\begin{array}{l}\text { My assessment is more hypothesis directed than } \\
\text { in previous years }\end{array}$ & $61.3 \%(n=19)$ & $32.3 \%(n=10)$ & 0 & $6.5 \%(n=2)$ & 0 \\
\hline 3. & $\begin{array}{l}\text { I understand why it is important for nurses to be } \\
\text { able to make nursing diagnoses }\end{array}$ & $71 \%(n=22)$ & $25.8 \%(n=8)$ & 0 & $3.2 \%(n=1)$ & 0 \\
\hline 4. & I know how to construct a nursing diagnosis & $67.7 \%(n=21)$ & $22.6 \%(n=7)$ & 0 & 0 & $9.7 \%(\mathrm{n}=3)$ \\
\hline 5. & $\begin{array}{l}\text { I feel more competent in prioritizing my nursing } \\
\text { diagnoses }\end{array}$ & $58.1 \%(\mathrm{n}=18)$ & $38.7 \%(n=12)$ & $3.2 \%(\mathrm{n}=1)$ & 0 & 0 \\
\hline 6. & I feel more competent in generating hypothesis & $58.1 \%(\mathrm{n}=18)$ & $32.3 \%(n=10)$ & $6.5 \%(n=2)$ & 0 & $3.2 \%(n=1)$ \\
\hline 7. & $\begin{array}{l}\text { I am able to plan nursing interventions that are } \\
\text { relevant to the nursing diagnosis }\end{array}$ & $61.3 \%(n=19)$ & $35.5 \%(\mathrm{n}=11)$ & 0 & $3.2 \%(n=1)$ & 0 \\
\hline 8. & $\begin{array}{l}\text { Having the nine step process made doing my case } \\
\text { presentation much easier }\end{array}$ & $74.2 \%(\mathrm{n}=23)$ & $16.1 \%(n=5)$ & $6.5 \%(n=2)$ & 0 & $3.2 \%(n=1)$ \\
\hline 9. & $\begin{array}{l}\text { I think using the nine step process has improved } \\
\text { my critical thinking and clinical problem solving } \\
\text { ability }\end{array}$ & $51.6 \%(n=16)$ & $38.7 \%(\mathrm{n}=12)$ & $6.5 \%(n=2)$ & 0 & $3.2 \%(n=1)$ \\
\hline 10. & $\begin{array}{l}\text { I feel more competent using the nursing process } \\
\text { than in previous years }\end{array}$ & $74.2 \%(n=23)$ & $22.6 \%(n=7)$ & 0 & $3.2 \%(\mathrm{n}=1)$ & 0 \\
\hline 11. & $\begin{array}{l}\text { I feel competent in using the nursing process in } \\
\text { real life nursing care situations }\end{array}$ & $45.2 \%(n=14)$ & $51.6 \%(n=16)$ & 0 & $3.2 \%(n=1)$ & 0 \\
\hline 12. & $\begin{array}{l}\text { I feel competent using nursing diagnoses in real } \\
\text { life nursing care situations. }\end{array}$ & $54.8 \%(n=17)$ & $41.9 \%(n=13)$ & 0 & $3.2 \%(n=1)$ & 0 \\
\hline
\end{tabular}

agree or strongly agree) were on the items related to improved critical thinking and problem solving abilities, made case presentation easier, and constructing a nursing diagnosis. Since the intervention was developed and implemented in this student group by the facilitators in this course, literature to explain student responses is limited. There is, however, literature that supports the usefulness of using systematic and more structured approach to problem solving. The importance of using a 'method' in problem solving in order to guide the mental activity stages one uses to originate and apply knowledge has been described (Edmund, 2007:1). Using a method in problem solving organises and clarifies our thoughts, prevents aimless wan- dering and helps to shape ideas. It provides an organised approach or system which in turn leads to increased self confidence and is a repeatable and remembered procedure. Having a systematic approach also aids in the transfer of learning, encourages conceptual thinking and trains for change and innovation (Edmund, 2007:1). It was also reported that receiving problem solving training can lead to greater positive affect, higher job satisfaction and higher life satisfaction (Ayres \& Malouff, 2007:279).

\section{Conclusion and recommendations}

In this paper a study to determine the usefulness of an intervention devel- oped by the facilitators in a PBL Level III nursing course is described. The data indicate that the students were satisfied with the nine step problem solving method and felt that it improved their ability to diagnose and plan patient care. The researchers feel that the data supports continued use of this strategy for students in this course in the following years. It is recommended that further research be. performed to determine if the same effect would occur with future groups in this course.

\section{Acknowledgements}

The authors wish to acknowledge the skilled contribution of Mr. Innocent Myeni, the research assistant on this 
project. Mr. Myeni was responsible for the data entry and preliminary analysis of the data.

\section{References}

AYRES, J \& MALOUFF, JM 2007: Problem-solving training to help workers increase positive affect, job satisfaction, and life satisfaction. European Journal of Work and Organizational Psvchology. 16 (3): 279-294.

BURKHART, L 2006: Integrating NNN Into Nursing Education: A Case Study. International Journal of Nursing Terminologies and Classifications. 17(1): 22.

CALLIN, M \& CILISKA, D 1983: Revitalizing problem solving with triple jump. Canadian Nurse. 79: 41-44.

DOENGES, ME \& MOORHOUSE,MF 2003: Application of Nursing Process and Nursing Diagnosis: An interactive text for diagnostic reasoning. (4 $4^{\text {th }}$ edition). Philadelphia: F.A. Davis Company.

EDMUND, NW 2007: The Supremacy of Method in Problem Solving. Problem Solving Headquarters. Available at: http: www.problemsolving.net/ supremacy.html. Accessed on 19/09/07.

LEE, M \& BRYSIEWICZ, P 2008: Enhancing problem solving and nursing diagnosis in year III Bachelor of Nursing students. Nurse Education Today. In press.

MAKHATHINI, JTN \& UYS LR 1996: An evaluation of the problem-solving ability of diplomats from a comprehensive nursing programme. Nurse Education Todav, 16: 340-349.

MÜLLER-STAUB, M; NEEDHAM,I; ODENBREIT, M; LAVIN, M \& VAN ACHTERBERG, T 1996: Improved Quality of Nursing Documentation: Results of a Nursing Diagnoses, Interventions, and Outcomes Implementation Study. International Journal of Nursing Terminologies and Classifications. 18(1): 5-17.

SMITH HIGUCHL, KA\& DONALD,JG 1996: Thinking Processes Used by Nurses in Clinical Decision Making. Journal of Nursing Education. 41(4):
145-153.

STATPAC INC 2007: Designing Surveys and Questionnaires. Questionnaire Design General Considerations. Available at: http: www.statpac.com. Accessed on 23/07/07.

VOLPATO, MP 2003: Nursing Diagnosis in Medical-Surgical Patients. International Journal of Nursing Terminologies and Classifications. Avaliable at: http://findarticles.com/p/ articles/mi_qa4065/is_200310/ai_n 9318744/. Accessed 07/17/07. 